\title{
Bovine Mastitis: Prevalence, Risk Factors, Major Pathogens and Antimicrobial Susceptibility Test on the Isolates around Addis Ababa, Central Ethiopia
}

\section{Tesfaye B*}

Regional Animal Health Diagnostic Laboratory, Ethiopia

Research Article

Volume 2 Issue 5

Received Date: September 20, 2017

Published Date: December 18, 2017

Laboratory, Assela, Oromiya, Ethiopia, Tel: +25193386496; Email: teyobeku@gmail.com

\section{Abstract}

A total 351 lactation cows were investigated during the study period. Out of total 351 lactation cows the overall prevalence of mastitis were $80(22.79 \%)$ (Table 1), where lower $5(1.99 \%)$ and higher 73 (20.79\%) were respectively by clinical and sub clinical type of mastitis. And the prevalence of mastitis was lower $20.94 \%$ and higher $24.13 \%$ in Sululta and Bareh districts respectively. From examined lactating cows $7.40 \%$ was at least 1 teat blind.

From currently tested few isolates using selected antimicrobial agents, all susceptible for Chloramphenicol and Gentamycin except one each isolates of S.aureus and micrococcus spp for both and C.pyogenes for Chloramphenicol and CNS for Gentamycin which shows intermediate. Similarly most of the isolates susceptible to Amoxycillin except some isolates of S. aureus, Str.uberis, CNS and C. pyogenes. However, high resistance was observed by most of isolates to Penicillin and tetracycline which are drugs currently in use for mastitis therapy in the study area.

Prevalence of mastitis, particularly, the subclinical one could bring about major economic losses in dairy cows without notice as result of reduced milk production, poor growth or mortality of suckling calves and dam health.

Keywords: Clinical Mastitis; Subclinical Clinical Mastitis; Antimicrobial; Susceptible; Isolates

Abbreviations: CMT: California Mastitis Test; CNS: Coagulase Negative Staphylococci; masl: Meter above Sea Level; NMC: National Mastitis Council

\section{Introduction}

Livestock represent a major national resource and form an integral part of the agricultural production system. Ethiopia holds large potential for dairy development due to its large livestock population and the favorable climate for improved and high yielding breeds. Given the considerable potential for generation of income and employment, the development of small holder dairy sector in Ethiopia, has a promising future and can contributes significantly to poverty alleviation improved nutrition in the country. According to Ahmed M [1], milk 


\section{Open Access Journal of Veterinary Science \& Research}

production during the 1990s expanded at an annual rate of $3.0 \%$ compared to $1.63-1.66 \%$ during the preceding three decades, with the expected growth in income ,increased urbanization and improved policy environment [2]. In Ethiopia it is estimated that $82 \%$ of the milk is supplied unpasteurized by intra and peri-urban producers to consumers, while only $18 \%$ is supplied by dairy enterprises in pasteurized form [3].

Mastitis is an inflammation of mammary gland, primary resulting from in invasion of the mammary gland by pathogenic microorganisms through the teat canal resulting in physical, chemical, pathological and bacteriological changes in glandular tissues and milk. Mastitis has been recorded as one of the major diseases of economic importance in dairy industry worldwide. It causes greater economic loss; much of the losses are related to production loss from inflammation of the infected quarters [4].

Owing to the heavy financial implication involved and the inevitable existence of latent infection, mastitis is obviously an important factor that limits dairy production. Evidence to date shows that affected dairy cows may loss $15 \%$ of their production and the affected quarter a $30 \%$ reduction in productivity .To these gross losses could be added losses associated with its keeping quality and manufacturing processes [5].

The most common pathogen comprises contagious bacteria mainly S.aureus and S.agalactae and environmental bacteria mainly coli forms and some species of streptococci that are commonly present in the environment [6].

Bale is one of a highly potential cereal-livestock zone where dairy activities play a significant role in the livelihood of farmers in the area. Considering the potentiality of the area and the economic significance of dairy production to the local community; there have been repeated efforts by governmental and non-governmental aid organizations to improve the dairy productivity and increased milk markets than other rural areas. Due to the above mentioned reasons and the economic capacity of the peasants' small-holder dairy production with crossbred dairy cattle is a common practice in the area. Yet, the information on the prevalence of sub clinical mastitis in the area is lacking and what available is fragments of information from cases of clinical mastitis that has been presented to veterinary clinic for the treatment.

\section{Materials and Methods}

\section{Study Area}

This cross- sectional study was conducted on lactating cows in Sululta and Bareh districts of Finfinne surrounding special zone of Oromia regional state, Central Ethiopia. Sululta district is located $40 \mathrm{~km}$ from Addis Ababa with an altitude ranges from 2100 to 2593 meters above sea level (m.a.s.l). And Bareh Sululta district is located $30 \mathrm{~km}$ from Addis Ababa with an altitude ranges from 2000 to 2514 meters above sea level (m.a.s.l).

\section{Study Population}

Study were conducted in Sululta and Bareh districts of Finfinne surrounding special zone of Oromia regional state, a total 351 heads of cross and local breeds of lactating cows kept under small dairy holder herds kept under extensive and semi extensive husbandry practice.

\section{Study Design and Period}

The study of bovine mastitis was determined using cross- sectional study at cow and quarter level based on clinical manifestations for clinical mastitis and indirect test (California mastitis test and Culture) for sub clinical mastitis.

\section{Sample Size Determination and Sampling Strategy}

The sample size was calculated according to the formula given by Thrusfield (2005) [7]. It is calculated by taking $(89.54 \%)$ estimated prevalence from previous report by Argaw and Tolosa (2008) [8]. Therefore, the calculated sample size were 144 lactating cows from each district, but to increase the probability of getting positive lactating cows 63cows was taken additionally. Thus, the total sample size was 351and 95\%confidence levels and $5 \%$ precision level. Simple random sampling method will be employed to select the individual dairy cow.

$$
\mathrm{N}=\frac{1.96^{2^{*}} \operatorname{Pexp}(1-\mathbf{p e x p})}{\mathrm{d}^{2}}
$$

Where $\mathrm{n}=$ require sample size, $\mathrm{Pexp}=$ expected prevalence, $d=$ desired absolute precision

\section{Study Methodology}

Data regarding the different potential risk factors (age, parity, and lactation stage, housing conditions, previous 
history of mastitis and husbandry system) were collected for 351 lactating cows from farm records when available and by interviewing the cows' owner when not. Clinical examination of the udder, screening using the California mastitis test (CMT) and bacteriological examination also were carried out.

Data Collection: Data on each sampled cow were collected in properly designed form (Annex 1).

Clinical Inspection of the Udder: The udder was examined clinically, using visual, then through palpation to detect possible swelling, pain, and disproportional symmetry, blindness of teats and discoloration of milk for the presence of mastitis [9].

Detection of Mastitis: The Californian mastitis reagent was used to screen cows with sub clinical mastitis milk sample collection was according to the procedures recommended by national mastitis council [10]. The result of the test was indicated on the basis of gel formation. The interpretation (grades) of the CMT was evocated and the results graded as 0 for negative and trace 1, 2 and 3, for positive [9] Annex 2.

\section{Microbial Investigation of Mastitis}

Milk Sample Collection: The milk samples were taken from cows not treated early with either intra mammary or systematic antimicrobials agents. For good collection of sample the teat was wiped thoroughly with $75 \%$ ethyl alcohol. The sterile collection of bottle was used and the first streams of milk from each quarter were discarded. The milk sample then held in an ice box for transportation to the laboratory. In laboratory samples were cultured immediately or stored at $+4 \circ \mathrm{C}[10]$.

Direct Microscopy: The milk sample was centrifuged and stained smear made from the deposit. A Gram stain was used routinely. The Zehil Neelson staining is performed for rare cases when bacteria such as $M$. bovis are suspected [9].

Culture: Before milking, milk samples were collected aseptically for microbiological culture, according to the procedures of the National Mastitis Council, 1999.Culturing of milk sample collected from individual cows, in search for mastitis producing organisms in standard of examination for mastitis [6]. The bacteriological culture will be formed following the microbiological technique [9] and microbiological producers for the diagnosis of bovine mastitis infection [10].

Antimicrobial Sensitivity Testing: Selected isolates were tested for sensitivity to different antimicrobials which used commonly in the area. Using in-vitro diffusion (Kirby-Baur method) as described by Quinn PJ [9] the procedure for the preparation of inoculation of 6 hour cultured broth cross-checked with McFarland, to the Mueller Hinton agar and disc application .After measuring the zone of inhibition, it was classified as sensitive, intermediate and resistant according to National Committee for Clinical Laboratory Standard (NCCLS) break point to interpret the inhibition zone [9].

Data Management and Analysis: Data which was collected through, history, clinical inspection, CMT, pathogenic bacteria isolation and identification and antimicrobial sensitivity test result was enter into data base management software Microsoft Excel computer program and analyzed using SPSS 20 version .The prevalence was expressed using percentage. The association among and between the considered risk factors were tested using Chi square ( $\chi 2$ ), Odds ratio (OR) and determination of OR Confidence interval. The significance of association was also expressed using pvalue at 0.05 .

\section{Result}

\section{Prevalence}

A total 351 lactation cows were investigated during the study period. Out of total 351 lactation cows the overall prevalence of mastitis were $80(22.79 \%)$ (Table 1), where lower 5 (1.99\%) and higher 73 (20.79\%) were respectively by clinical and sub clinical type of mastitis. And the prevalence of mastitis was lower $20.94 \%$ and higher $24.13 \%$ in Sululta and Bareh districts respectively. From examined lactating cows $7.40 \%$ was at least 1 teat blind. As shown in Table 2 out of 1404 quarters examined during study period $130(9.25 \%)$ were positive for mastitis while 49 (3.49\%) blind.

\begin{tabular}{|c|c|c|c|c|c|}
\hline \multirow{2}{*}{ Districts } & \multicolumn{2}{|c|}{ Mastitis condition } & \multirow{2}{*}{$\begin{array}{c}\text { Total No. Examined n } \\
\text { (\%) }\end{array}$} & Results n (\%) & $\begin{array}{c}\text { At least 1teat blind } \\
\text { cow }\end{array}$ \\
\cline { 2 - 3 } & Clinical n (\%) & Subclinical n (\%) & & & $17(11.48)$ \\
\hline Sululta & $4(2.70)$ & $27(7.69)$ & $148(42.16)$ & $31(20.94)$ & $9(4.43)$ \\
\hline Bareh & $3(2.17)$ & $46(38.59)$ & $203(57.83)$ & $49(24.13)$ & $26(7.40)$ \\
\hline Total & $5(1.99)$ & $73(20.79)$ & $351(100)$ & $80(22.79)$ & \\
\hline
\end{tabular}

Table 1: Prevalence of Clinical and subclinical mastitis during study period. 


\section{Open Access Journal of Veterinary Science \& Research}

\begin{tabular}{|c|c|c|c|}
\hline \multirow{2}{*}{ Quarter } & \multicolumn{3}{|c|}{ No examined } \\
\cline { 2 - 4 } & Negative (\%) & Positive No (\%) & Blind No (\%) \\
\hline Right back & $351300(85.84)$ & $35(9.97)$ & $16(4.55)$ \\
\hline Right front & $351313(89.17)$ & $29(8.26)$ & $9(2.54)$ \\
\hline Left back & $351299(85.18)$ & $35(9.97)$ & $7(4.84)$ \\
\hline Left front & $351313(89.17)$ & $31(8.83)$ & $\mathbf{4 9}(3.49)$ \\
\hline Over all & $\mathbf{1 4 0 4} 1225(87.25)$ & $\mathbf{1 3 0}(\mathbf{9 . 2 5})$ & \\
\hline
\end{tabular}

Table 2: Quarter level prevalence of mastitis during study period.

\section{Bacterial Isolation and Antibiotic Sensitivity Testing}

From cultured samples, the bacteria genera/ species and isolated were as in Table 3 with high prevalence were
Staphylococcus aureus (46.63\%), Coagulase negative Staphylococcus (13.47\%) and Corynebacteriumbovis, Streptococcus uberis and Micrococcus spp (5.88\%).

\begin{tabular}{|c|c|c|}
\hline No. & Types of bacterial isolates & Number (\%) \\
\hline 1 & Staphylococcus aureus & $90(46.63)$ \\
\hline 2 & Streptococcus uberis & $11(5.88)$ \\
\hline 3 & Streptococcus intermidius & $7(3.74)$ \\
\hline 4 & Str.agalactae & $4(2.07)$ \\
\hline 5 & CNS (Coagulase negative Staphylococcus) & $26(13.47)$ \\
\hline 6 & Micrococcus spp & $11(5.88)$ \\
\hline 7 & Bacillus cerues & $7(3.74)$ \\
\hline 8 & Proteus Spp & $8(5.00)$ \\
\hline 9 & Corynebacteriumbovis & $11(5.88)$ \\
\hline 10 & Corynebacteriumpyogenes & $9(4.81)$ \\
\hline 11 & Psudotuberculosis & $5(3.12)$ \\
\hline 12 & E.coli & $4(2.13)$ \\
\hline
\end{tabular}

Table 3: Bacterial isolates during all season.

As shown in Table 4 bellow from currently tested few isolates using selected antimicrobial agents, all susceptible for Chloramphenicol and Gentamycin except one each isolates of S.aureus and micrococcus spp for both and C.pyogenes for Chloramphenicol and Coagulase negative Staphylococcus for Gentamycin which shows intermediate. Similarly most of the isolates susceptible to Amoxycillin except some isolates of Staphylococcus aureus, Streptococcus uberis, Coagulase negative Staphylococcus and Corynebacteriumpyogenes. However, high resistance was observed by most of isolates to Penicillin.

\begin{tabular}{|c|c|c|c|c|c|c|c|c|c|c|c|c|c|c|c|c|}
\hline \multicolumn{17}{|c|}{ Response To Application Of Antimicrobial Disks (\%) } \\
\hline \multirow{2}{*}{$\begin{array}{l}\text { Bacterial } \\
\text { isolates }\end{array}$} & \multirow{2}{*}{$\mathbf{N}$} & \multicolumn{3}{|c|}{$\mathbf{C 3 0}$} & \multicolumn{3}{|c|}{ CN10 } & \multicolumn{3}{|c|}{ TE30 } & \multicolumn{3}{|c|}{ P10 } & \multicolumn{3}{|c|}{ AML25 } \\
\hline & & $\mathbf{S}$ & I & $\mathbf{R}$ & $\mathbf{S}$ & I & $\mathbf{R}$ & $\mathbf{S}$ & I & $\mathbf{R}$ & $\mathbf{S}$ & I & $\mathbf{R}$ & $\mathbf{S}$ & I & $\mathbf{R}$ \\
\hline & & $59(9)$ & & & of & $\overline{(9.3}$ & & (J1) & $14(21.8$ & $30(46.8$ & $19(29.6$ & $3(20$. & & $39(60.9$ & $15(23.4$ & $10(15.6$ \\
\hline S.aureus & 64 & 8) & p(7.81. & - & 2) & ) & - & 5) & 7) & 7) & 8) & 1) & & 3) & 3) & 2) \\
\hline $\begin{array}{l}\text { treptocouber } \\
\text { S }\end{array}$ & 5 & $5(100)$ & - & - & $5(100)$ & - & - & $2(40)$ & - & $3(60)$ & $1(20)$ & - & $4(80)$ & $2(40)$ & $1(20)$ & $2(40)$ \\
\hline S.intermidius & 2 & $2(100)$ & - & - & $2(100)$ & - & - & - & $1(50)$ & $1(50)$ & - & - & $2(100)$ & $2(100)$ & - & - \\
\hline
\end{tabular}




\section{Open Access Journal of Veterinary Science \& Research}

\begin{tabular}{|c|c|c|c|c|c|c|c|c|c|c|c|c|c|c|c|c|}
\hline & & & 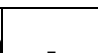 & & $14(93.3$ & $3(6.66$ & & $5(33.33$ & $2(13.33$ & $8(53.33$ & $32(13.3$ & $4(26.6$ & & $7(46.66$ & $2(13.33$ & \\
\hline CNS & & $15(100)$ & - & 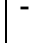 & 3) & ) & & ) & ) & ) & ) & ) & 60) & ) & ) & $6(40)$ \\
\hline $\begin{array}{c}\text { micrococcus } \\
\text { spp }\end{array}$ & 5 & $3(60)$ & $2(40)$ & - & $4(80)$ & $1(20)$ & - & $2(40)$ & $1(20)$ & $2(40)$ & $2(40)$ & - & $3(60)$ & $4(80)$ & $1(20)$ & - \\
\hline B.cereus & 2 & $2(100)$ & - & - & $2(100)$ & - & - & - & $2(100)$ & - & $1(100)$ & - & $1(50)$ & $1(50)$ & $1(50)$ & 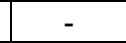 \\
\hline Proteus Sps & 2 & $2(100)$ & - & - & $2(100)$ & - & - & 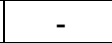 & $\begin{array}{ll}- \\
\end{array}$ & $2(100)$ & - & - & $2(100)$ & $2(100)$ & - & - \\
\hline C.bovis & 4 & $4(100)$ & - & - & $4(100)$ & - & - & - & $2(50)$ & $2(50)$ & $2(50)$ & - & $2(50)$ & $3(75)$ & $1(25)$ & \\
\hline & & $2(66.66$ & $1(33.3$ & & & & & $1(33.33$ & $2(66.66$ & & $1(33.33$ & & $2(66.6$ & 62666.66 & & $1(33.33$ \\
\hline C.py & 3 & ) & 3) & -1 & $3(100)$ & - & & ) & ) & - & ) & - & 6) & ) & - & ) \\
\hline Str.agalactae & 1 & $1(100)$ & ( & - & $1(100)$ & - & - & - & $1(100)$ & - & - & - & $1(100)$ & $1(100)$ & - & - \\
\hline E.coli & 2 & $2(100)$ & - & - & $2(100)$ & - & - & - & $1(50)$ & $1(50)$ & - & $1(50)$ & $1(50)$ & $1(50)$ & $1(50)$ & - \\
\hline $\begin{array}{c}\text { psudotubercu } \\
\text { osis } \\
\end{array}$ & 1 & $1(100)$ & - & - & $1(100)$ & - & & $1(100)$ & - & - & - & - & $1(100)$ & $1(100)$ & - & - \\
\hline Total & 6 & & & & & & & & & & & & & & & \\
\hline
\end{tabular}

Table 4: Antibiotic sensitivity testing.

Keys: N=Number of observations, S: Susceptible, I=Intermediate, R=Resistance, $\mathrm{C}=$ Chloramphenicol, $\mathrm{CN}=\mathrm{Gentamycin}$, $\mathrm{TE}=$ Tetracycline, $\mathrm{P}=$ Penicillin, $\mathrm{AML}=$ Amoxycilli

\section{Discussion}

In this study, the overall bovine mastitis prevalence is $80(22.79 \%)$. The prevalence higher compared to the others study finding done on mastitis elsewhere in Ethiopia such as $52.27 \%$ by Abunna, et al. [11], 34.9\%, $74.7 \%$ by Zeryehun, et al. [12] and Ashenafi [13] who reported $75 \%$ prevalence. This might be due to management system the farmers have practiced in the study area. Up on taking history on the cows' production of milk, they only give less than 2 liter/day. Local Zebu breed are low in milk production and resistant to mastitis [14]. Higher yielding cows have been found more susceptible to mastitis owing to position of teats, udder, and anatomy of teat cannel making them prone to injury, and due to fewer efficacies of pathogenic cells in higher yielding cows associated to dilution $[6,15]$.

The clinical mastitis prevalence in this study was 5 (1.99\%) which was comparable with that of Tesfaye [16], who reported $7.3 \%$ in Adama, and Adugna [17], who reported 5.7\% in Dire Dawa and Haramaya University Dairy farm. Most of the time when comparing clinical and sub-clinical mastitis, clinical mastitis is lower than that of sub-clinical mastitis and this is because of treatment of clinical mastitis is commonly practiced [16].

Dairy farms in the study area usually complain about the decrease in milk yield irrespective of adequate feed provision and de worming practice. The high prevalence of sub-clinical mastitis may be due to attributed to improper milking hygiene, poor house hygiene, lack of post milking teat dipping and practicing of milk by contact labors use of lubricant, absence of order in milking cows of different ages. Moreover, its occurrence was high in dairy farms without noticeable in farm treatment as Radostitis, et al. [6] and Quinn, et al. [9] provide the same reasoning.

From currently tested few isolates using selected antimicrobial agents, all susceptible for Chloramphenicol and Gentamycin except one each isolates of S.aureus and micrococcus spp for both and C.pyogenes for Chloramphenicol and CNS for Gentamycin which shows intermediate. Similarly most of the isolates susceptible to Amoxycillin except some isolates of $S$. aureus, Str.uberis, CNS and C. pyogenes. However, high resistance was observed by most of isolates to Penicillin and tetracycline which are drugs currently in use for mastitis therapy in the study area.

Prevalence of mastitis, particularly, the subclinical one could bring about major economic losses in dairy cows without notice as result of reduced milk production, poor growth or mortality of suckling calves and dam health.

\section{Acknowledgement}

First and foremost, I like to thank the heavenly father God for giving my strength and patience during my all life and study program. I would like to express my deep sincerely appreciation and thanks to Dr. Henok Ayalew, for his intellectual guidance, close supervision and devotion of time in criticizing this paper. 


\section{Open Access Journal of Veterinary Science \& Research}

\section{Conflict of Interest}

I declare that this paper presents the work carried out by myself and does not incorporate with the acknowledgement of any material and finance

\section{References}

1. Ahmed M, Bezabih E, Mohammed J, Simeon E (2003) Analysis of Economic and nutritional impact of market oriented dairy production in the Ethiopian high lands. In: Socio-economic and policy research working paper, livestock policy Analysis program ILRI, pp: 27.

2. Kelay B (2002) Analysis of dairy cattle breeding practices in selected areas of Ethiopia.

3. Ameni G, Aseffa A, Engers H, Young D, Gordon S, et al. (2007) High prevalence and increased severity of pathology of bovine tuberculosis in Holsteins compared to zebu breeds under field cattle husbandry in central Ethiopia. Clinical and Vaccine Immunology 14(10): 1356-1361.

4. Erskine RJ (2001) Mastitis control in dairy farms. In: Radostits OM (Eds.), Herd health, food animal production medicine, $3^{\text {rd }}$ (Edn.), WB Saudres Company, Philadelphia, Pennsylvania.

5. Heeschen WH (1997) Milk hygiene and milk safety the European and international market. ILLER Milchwirtscraftliche for Schungus Berehte 50: 53-77.

6. Radostits OM, Gay CC, Blood DC, Hinchlif KW (2007) Mastitis. In: Veterinary medicine $9^{\text {th }}$ (Edn.), Harcourt Ltd, London, pp: 174-758.

7. Thrusfield M (2005) Veterinary Epidemiology, UK, Black well science. $3^{\text {rd }}$ (Edn.), pp: 178-197.

8. Argaw K, Tolosa T (2008) Prevalence of sub clinical mastitis in small holder dairy farms in Selale, North Shoa Zone,Central Ethiopia. The Internet Journal of Veterinary Medicine 5(1).
9. Quinn PJ, Carter ME, Markey BK, Carter GR (2002) Clinical Veterinary microbiology. Harcourt publishers, Virginia, pp: 331-344.

10. NMC (1999) Current Concept in bovine mastitis National mastitis Council (NMC). $3^{\text {rd }}, 1840$ Wilsonblud, Arlinton, VA 22201. pp: 397-432.

11. Abunna F, Fufa G, Megersa B, Regassa A (2013) Bovine Mastitis: Prevalence, Risk Factors and Bacterial Isolation in Small-Holder Dairy Farms in Addis Ababa City, Ethiopia. Global Veterinaria 10(6): 647-652.

12. Zerehun T, Aya $T$, Bayecha $R$ (2013) Study on prevalence, bacterial pathogens and associated risk factors of bovine mastitis in small holder dairy farms in and around Addis Ababa, Ethiopia. J Anim Plant Sci 23(1): 50-55.

13. Ashenafi G (2008) Prevalence of bovine mastitis, identification of the causative agent and drug sensitivity test in and around kombolcha. DVM Thesis FVM, Haramaya University 17: 41-46.

14. Almaw G, Molla B (2000) prevalances and etiology of mastitis in camels (Camelusdermoderies) in Eastern Ethiopia. J Camel pract Res 7: 97-100.

15. Schalm W, Carrlole F, Jain J (1971) Bovine mastitis Philadelphia: Led and Teliger pp: 1-21.

16. Tesfaye A (2007) Small scale dairy farming practice and cross-sectional study of mastitis in Nazareth East Shoa MSc. Thesis Faculty of Veterinary Medicine Addis Ababa University.

17. Adugna B (2008) Cross sectional study of mastitis in Dire Dawa and Haramaya University dairy farms, prevalence isolation and identification of pathogens and Antimicrobial sensitivity testing, Eastern Ethiopia. DVM thesis, FVM Haramaya University. 